\title{
AVANÇOS E LIMITES \\ Na Historiografia Da Legislação Urbanística No Brasil
}

\author{
SARAH FELDMAN
}

R E S U M O Este trabalho tem por objetivo analisar a produção recente no campo da história da legislação urbanistica no Brasil, procurando detectar avanços e limites para a reflexão sobre desenvolvimento urbano e práticas urbanisticas. O texto organiza-se em três eixos analiticos. Em primeiro lugar, procura-se situar os trabalhos no processo de disseminação de estudos da história urbana no Brasil, vinculando-os ao movimento de ampliação do território da história que ocorre na Europa e nos Estados Unidos, a partir dos anos 60, com a chamada História Nova. Em segundo, baseado em um panorama da produção recente, são detectadas as vertentes dominantes e emergentes nos trabalhos sobre legislação. Em terceiro, são discutidos dois aspectos que se configuram como lacunas na historiografia da legislação: o lugar ocupado pelas normas, a partir do momento em que idéias e práticas urbanisticas têm um espaço institucionalizado na administração pública; e o lugar dos pressupostos modernistas na legislação brasileira, visto que o movimento modernista formula a proposta de um novo sistema legal para o urbanismo.

P A L A V R A S - C H A V E Legislação urbanistica; história; movimento moderno.

\section{HISTÓRIA NOVA, HISTÓRIA URBANA E HISTÓRIA DA LEGISLAÇÃO URBANÍSTICA}

A partir dos anos 80 , um número crescente de pesquisas vem-se direcionando para a construção da historiografia das cidades brasileiras, estabelecendo um marco temporal em relação à escassa produção anterior nessa área. Um elemento a destacar - determinante para uma avaliação do estado da arte desse conjunto de trabalhos - é seu caráter multidisciplinar, uma vez que vêm sendo elaboradas, majoritariamente, por arquitetos, urbanistas, planejadores, geógrafos e outros profissionais vinculados à questão urbana. Nesse sentido, a produção em curso pode ser inscrita no processo de ampliação do território da história que, desde os anos 60, se dissemina na Europa e nos Estados Unidos, a partir do movimento que tem origem no grupo de historiadores ligados à revista Annales d'Histoire Économique et Sociale, surgida em 1929, na França, como reação aos paradigmas do historismo desenvolvido no século XIX. ${ }^{1}$

O objetivo fundamental do grupo é, desde o início, combater os rígidos limites colocados pela visão do historismo, que tem no historiador alemão Leopold von Ranke sua maior expressão. À história baseada unicamente nos grandes acontecimentos e nas fontes documentais oficiais, restrita à política e feita somente por historiadores profissionalizados, contrapõem a aproximação da história a outras disciplinas e a ampliação dos objetos da história e do campo de fontes documentais.

Nessa busca de ampliação do território da história e da interdisciplinaridade está implícito o questionamento à especialização do historiador, que resultou da institucionaliza-

10 grupo ficou conhecido como École des Annales. A revista teve quatro denominações: Annales d'Histoire Économique et Sociale (1929-39); Annales d'Histoire Sociale (1939-42, 1945); Mélanges d'Histoire Sociale (1942-44) ; Annales: Économies, Sociétés, Civilisations (1946). 
2 Braudel, F. 1959:49.

3 Veyne, P., 1971:43.

4 Burke, P., 1991:15.

5 Burke, P. op. cit.; Borges, V. P., 1980; Ribeiro, R. J. et al., 1994; entre outros.

6 Ribeiro, R. J., op. cit.:13.

7 Burke, P., 1990:12.

8 Braudel, F., op. cit.:44-54. ção acadêmica da visão rankeana, e a afirmação da idéia de que tudo tem história, tudo tem um passado que pode ser reconstruído, não se reconhecendo, portanto, a existência de uma história com $\mathrm{H}$ maiúsculo. Assim, em contraposição a uma história referenciada em fatos que, nas palavras de Braudel, não passam de "espumas nas ondas do mar da história", propõem a "história total". ${ }^{2}$ Os fatos não existem isoladamente, mas constituem um tecido, têm uma organização na qual desempenham o papel de causa, fins, acasos etc., e cabe ao historiador "reencontrar essa organização". ${ }^{3}$ Em termos metodológicos, a diretriz principal diz respeito à ampliação das fontes: não apenas escritas, mas também orais, imagéticas, estatísticas, etnográficas etc. A explicação histórica deve, nessa perspectiva, dar-se pela variedade de questionamentos que se revelam mediante o reconhecimento de "vozes variadas e opostas", e não pelo ideal de uma voz oficial da história. ${ }^{4}$

Somente a partir dos anos 60, a interdisciplinaridade proclamada desde os anos 20 se realiza, diluindo-se os rígidos limites entre o território da história e algumas áreas das ciências humanas. Nos anos 70, o movimento passa a denominar-se Nova História, dissemina-se pela Europa e Estados Unidos, e os historiadores a ele vinculados ampliam seu espaço nas instituições acadêmicas e conquistam o acesso às editoras e à mídia.

Várias questões vêm sendo levantadas quanto aos rumos tomados pelo movimento dos Annales, as quais não cabem ser desenvolvidas no âmbito deste texto. A própria expressão Nova História vem sendo questionada, uma vez que nunca foram abandonados os princípios elaborados no início do século. ${ }^{5}$ Há um debate em torno das relações dos historiadores com o materialismo histórico, as quais oscilam entre o reconhecimento de Marx como um precursor de muitas de suas idéias e a negação do método e dos conceitos marxistas. A vinculação dos historiadores à Academia também é questionada: o movimento, que se inicia marcado pelo inconformismo, pela negação da ortodoxia acadêmica, acaba, segundo alguns autores, por entrar no jogo intramuros da Academia, e os procedimentos considerados revolucionários convertem-se "em simples instrumentos para legitimação de trabalhos que graças a eles se inscrevem acadêmica e editorialmente". ${ }^{6}$

Outra questão levantada refere-se ao fato de a chamada Nova História ser considerada um movimento de disseminação de práticas e idéias relativas à historiografia, e somente se constituir como uma "escola" no período em que é liderado por Fernand Braudel, quando novos conceitos são elaborados, conformando uma concepção de história. ${ }^{7} \mathrm{~A}$ principal contribuição da Nova História ao pensamento e à prática da história seria, portanto, a introdução, por Braudel, de uma nova dimensão da história, que diz respeito à apreensão das forças profundas da história que só se deixam apreender e só atuam no tempo longo. Braudel decompõe a história em três planos escalonados, distinguindo tempo histórico/tempo geográfico, tempo social e tempo individual. A eles correspondem, respectivamente, as estruturas, as conjunturas, os acontecimentos. O tempo das estruturas é a longa duração, a quase imobilidade, uma vez que as estruturas permanecem constantes durante um tempo longo ou só evoluem de maneira imperceptível. O tempo das conjunturas são flutuações de dimensões diversas, oscilações cíclicas que se manifestam no contexto das estruturas. Os acontecimentos são engendrados pelas estruturas e conjunturas, são as rupturas ou o restabelecimento de equilíbrios. ${ }^{8}$

Mas em meio a todos os questionamentos, há uma concordância quanto à contribuição do grupo na expansão do campo da história, bem como na descoberta de novas fontes e novos métodos para explorá-las.

Sua importância está não apenas na dilatação do território da história como também do historiador, abrangendo temas e grupos sociais negligenciados pelos historiadores tradicionais. 
Como parte de tal processo, a história urbana desenvolve-se a partir da história social e, no panorama internacional, os anos 60 constituem um momento relevante, pois inicia-se a busca de demarcação de seus conteúdos. ${ }^{9}$ Um pressuposto que se impõe é assumir um ponto de ruptura no processo de constituição da cidade, enfatizando, dessa maneira, uma abordagem problematizada da urbe. Essa abordagem contrapóe-se à abordagem dominante na história da cidade, desde o século XIX, que tem como pressuposto teórico a noção de crescimento evolutivo ou de desenvolvimento, "que faz com que a(s) cidade(s) seja(m) considerada(s) um fato histórico, sempre o mesmo, um fenômeno cujas transformações (materialidade e função) constituem o objeto de pesquisa dos estudiosos" ${ }^{10}$ Nesse sentido, considera-se a cidade do século XIX um momento de ruptura no processo de urbanização e privilegia-se o estudo da cidade associada à idéia de modernidade. Nessa perspectiva, a cidade moderna é considerada essencialmente diferente, não podendo, portanto, ser abordada como mera descendente dos núcleos urbanos do passado. ${ }^{11}$

De modo geral, numa grande categoria denominada "história urbana", passam a enquadrar-se todos os estudos que tenham a cidade como locus, ocorrendo uma não-distinção entre o que é peculiar ao desenvolvimento da cidade e aquilo que diz respeito à cultura de forma geral. As posiçôes em torno dessa questão são diversas, com autores que consideram difícil, ainda hoje, demarcar o que é um trabalho de história urbana, autores que apregoam um campo específico para a história do urbanismo, e autores que entendem a história urbana como o estudo da forma urbana como resultante de complexas forças sociais, psicológicas e econômicas. ${ }^{12}$

Em The History of Urban and Regional Planning - an annotated bibliography, publicado em 1981, Anthony Sutcliffe faz um balanço dos trabalhos elaborados, em sua grande maioria, na Europa e Estados Unidos. Em suas conclusões, podem-se observar algumas semelhanças com a condição atual da história urbana no Brasil, principalmente em relação ao universo de pesquisas vinculadas às idéias e às práticas urbanísticas, tanto no que se refere ao perfil dos pesquisadores, como no que se refere aos limites na utilização de recursos teórico-metodológicos. Cabe destacar que a maioria absoluta dos trabalhos levantados por Sutcliffe são elaborados no período pós-60, o que confirma esse momento como um marco na expansão da área.

O autor mostra que a maioria dos trabalhos são elaborados por profissionais de diferentes áreas, mas vinculados à prática do planejamento urbano, e identifica uma imaturidade na historiografia do planejamento, a qual se manifesta sob vários aspectos: há, por um lado, a necessidade de se estabelecer um "pedigree histórico" para reforçar a identidade da profissão e, por outro, a busca das origens para explicar as frustrações devidas às limitações atuais do planejamento. Para Sutcliffe, a não-formação acadêmica dos autores na área de história faz que grande parte dos trabalhos não passem de catalogações de leis ou biografias de planejadores, que não estabelecem relaçóes com seus períodos, ou, ainda, estudos de planos de cidades que não se explicam pelos processos urbanos mais gerais. Ao mesmo tempo que detecta tais limites, Sutcliffe afirma que a historiografia realizada por profissionais atuantes e oriundos de todas as áreas das ciências sociais é de fundamental importância, uma vez que a vitalidade da história do urbanismo está, justamente, no duplo vínculo com prática e teoria.

Semelhantes questóes nos dizem respeito. A carência de teorização e discussão conceitual e metodológica da história já foi apontada na análise de um universo limitado da produção brasileira, elaborada por Filgueiras \& Fernandes (1998). Vivemos um
9 Sobre o debate em torno da história urbana nos anos 60, consultar Handlin, 0. e Burchard, J., 1963.

10 Bresciani, M. S. 1992:11.

11 Handlin, O., 1963. In: Handlin, O., Burchard, J., op. cit.; Bresciani, M. S., op. cit.

12 De Decca., E., 1991:9, e os textos de Tunnard, C. "A note on the pursuit of city planning history", e de Summerson, S. J., "Urban forms", in: Handlin, O., Burchard, J., op. cit. 
13 Sobre as referências aos trabalhos nos anos 70 , ver Leme, M. C., Pacheco, R., 1989. "A questão fundiária, imobiliária e os serviços urbanos: conceitos e referências teóricas em teses e dissertações recentes". Espaço e Debates, São Paulo, $n^{0} 28$, p.101-117. momento em que, a uma apropriação documental - uma verdadeira "saída dos armários" de relatórios, material iconográfico, planos, relatórios etc. - corresponde uma não-apropriação metodológico-conceitual da disciplina história, que se expressa, por um lado, na quantidade de pesquisas voltadas para a criação de bancos de dados e, por outro, no número significativo de trabalhos que se restringem a descrever cronologicamente planos, leis, relatórios etc.

Deve-se considerar que os trabalhos, no Brasil, além de sinalizarem a vitalidade de um campo temático multidisciplinar, constituem uma busca de ampliação de parâmetros teóricos e metodológicos para se transpor os limites interpretativos colocados pela pronunciada influência do referencial marxista - desenvolvido, sobretudo, pela sociologia francesa dos anos $70-$, o qual vinha marcando as pesquisas brasileiras. ${ }^{13}$ Assim, paralelamente ao esquadrinhamento das fontes documentais, que vem permitindo iluminar todo um universo de constituição da engenharia, arquitetura e urbanismo brasileiros que permanecia oculto, os trabalhos de história urbana refletem o deslocamento das interpretações fundamentadas exclusivamente em determinantes econômicos, em que as questôes fundiária, imobiliária e de serviços urbanos foram privilegiadas na explicação dos processos de estruturação urbana, para a incorporação de aspectos estético-culturais. Se, nos anos 70, os marcos teórico-conceituais em suas várias vertentes eram em grande parte explicitados ou reconhecíveis, nos trabalhos elaborados pós-80, com exceção daqueles vinculados à linha foucaultiana, tais questões vêm sendo minimizadas.

Nesse panorama, a legislação urbanística - aqui entendida como o conjunto de regulamentações referentes ao parcelamento, uso e ocupação do solo e às edificações - não foge à regra, com a agravante de não estar recebendo a devida atenção dos pesquisadores, embora seja o elemento constitutivo da disciplina do urbanismo mais desenvolvido, no Brasil, nas últimas cinco décadas. São poucos os trabalhos que vêm procurando inserir a legislação como fato histórico no interior de uma história-problema, no sentido apontado por Veyne (1971). Ainda que a referência à legislação esteja presente na maior parte dos estudos sobre o urbanismo no Brasil, a legislação é, de certa forma, naturalizada e, com raras exceções, ultrapassa o caráter de identificação das leis por meio da listagem e descrição de seus conteúdos.

Neste trabalho, procuramos levantar alguns pontos para a discussão dos caminhos, abordagens e métodos em curso na historiografia da legislação urbanística. O papel assumido pela legislação no urbanismo brasileiro constitui um campo nebuloso e pouco explorado. Nos setores de urbanismo das administrações municipais no Brasil, prevalece, há meio século, uma abordagem legalista, ou seja, a legislação é colocada como uma meta em si, e não como um instrumento, dentre outros, para atingir determinadas metas de desenvolvimento urbano. Se no período da Primeira República, quando começam a estruturar-se, nas administrações públicas, as seções de obras que evoluem para seções de urbanismo, a elaboração e execução dos planos de melhoramentos e, posteriormente, dos chamados planos de conjunto, impõem-se como atividade privilegiada de urbanistas oriundos dos cursos de Engenharia. A partir dos anos 40, ocorre um nítido deslocamento da esfera de atuação desses órgãos. Constrói-se um novo saber urbanístico - uma nova visão de atuação do Estado ante as novas formas de apropriação do espaço urbano - e os denominados órgãos de planejamento passam a atuar, fundamentalmente, como órgãos normativos. A tal mudança corresponde uma nova estrutura organizacional do setor, assim como a construção de um novo perfil do urbanista - o profissional generalista, com predominância de profissionais egressos dos cursos de arquitetura. É nesse momento que 
se dá uma fissura entre arquitetura e urbanismo: planejar passa a constituir-se como atividade desligada de projetar, e o zoneamento - abrangente ao conjunto da cidade e articulador de um conjunto de parâmetros urbanísticos em zonas funcionais - consolida-se como o principal instrumento de planejamento.

\section{O LUGAR DA LEGISLAÇÃo NA HISTORIOGRAFIA DO URBANISMO NO BRASIL}

No período anterior à década de oitenta, dois trabalhos destacam-se pela abordagem da legislação urbanística: a tese para concurso de cátedra na Escola Politécnica da Universidade de São Paulo, de Francisco de Paula Andrade, de 1966, e o livro de Nestor Goulart Reis Filho, de 1968. Embora Andrade coloque que não visa a "história", seu trabalho pode ser considerado pioneiro, pois fornece um quadro abrangente da legislação brasileira, desde o Império até a primeira metade do século XX, apontando suas relações com a legislação urbana portuguesa. Reis Filho, ao estudar a evolução urbana do Brasil nos séculos XVI e XVII, aponta os princípios reguladores e as instituições responsáveis por sua implementação, no âmbito da política urbanizadora no Brasil-colônia.

Da análise dos trabalhos publicados em livros, anais de encontros e seminários, dissertações de mestrado e teses de doutorado, no período pós-80, podem ser identificadas três vertentes dominantes nas pesquisas voltadas para a historiografia da legislação urbanística no Brasil. Uma primeira vertente enfoca os aspectos normativos referentes à propriedade fundiária, emanados pelo poder eclesiástico até a promulgação da Lei de Terras, em 1850, quando a terra adquire o estatuto de mercadoria. Os trabalhos de Marx (1991), Fridman \& Ramos (1992) e Fridman (1994) mostram como entre o regime jurídico do sistema de sesmarias do período colonial e a separação entre Igreja e Estado estrutura-se a propriedade fundiária no Brasil. Da distribuição gratuita de terras, passa-se à aquisição onerosa, o que define os limites da propriedade em favor do interesse público. Marx (op. cit.) mostra, de forma minuciosa, como persistem, por décadas, os privilégios dos grandes detentores de terra e os procedimentos do antigo sistema de distribuição de terras, e como, de forma tímida, os municípios se adaptam à nova realidade político-administrativa, a partir da lei de 1850 e sua regulamentação em 1854, mediante a prática dos loteamentos e dos códigos de posturas, atos e resoluções.

Esses trabalhos permitem detectar a constituição de um sistema legal em torno da propriedade privada - da exigência da escritura pública de compra e venda (1855) à criação do imposto predial (1878) e taxação de terrenos não-construídos em freguesias urbanas centrais (1897) - e como, já em fins do século XIX, se pode estabelecer uma relação entre tais medidas e o processo de valorização imobiliária e fundiária. Além disso, apontam que, juntamente com o aparato legal, ocorre uma estruturação da administração e novas funçōes se constituem no quadro administrativo municipal.

A segunda vertente caracteriza-se por estudos que têm como marco temporal a Primeira República, nos quais prevalece a interpretação da legislação como instrumento de dominação e normatização da vida das classes populares e de atividades que se incluem na esfera das ilegalidades urbanas, referenciadas nos pressupostos higienistas (Rolnik, 1983; Feldman, 1987; Lira, 1991; Marins, 1998). Nesses trabalhos, a lógica disciplinadora de um urbanismo saneador - expressão de um projeto político de intervenção do Estado na questão social nas cidades - é desvendada, tanto nas formas de habitação 
14 Sobre o zoneamento: Wilderode, D., 1995. "Operações interligadas: Quem ganha?" Anais do VI Enanpur, Brasília, 1995; Azevedo, D. T., 1993, 0 jogo das Interligadas, Dissertação de Mestrado, São Paulo, FGV; Wakisaka, T., 1990. Zoneamento de uso, ocupação do solo e produção do espaço urbano em São Paulo, Dissertação de Mestrado, São Paulo, FAU/USP; entre outros. Sobre instrumentos pós-Constituição de 1988: IPPUR/UFRJ, 1994. Questão urbana, desigualdades sociais e políticas públicas: avaliação do Programa Nacional de Reforma Urbana, Relatório de Pesquisa; Ribeiro, A. C. T., 1994. "Reforma urbana nos limites da modernização", Espaço e Debates, n.37, São Paulo, Neru; Alfonsin, B., 1997, "Instrumentos e experiências de regularização fundiária em áreas urbanas", Anais do VII Enanpur, Recife, p.1571-1579; entre outros.

15 Machado, R. et al., 1978. Danação da norma medicina social e constituição da psiquiatria no Brasil, Rio de Janeiro, Graal; Freire Costa, J., 1979. Ordem médica e norma familiar, Rio de Janeiro, Graal; Sevcenko, N., 1984. A revolta da vacina, São Paulo, Brasiliense; Costa, N. do R., 1987. "A Questão sanitária e a cidade", Espaço e Debates, n.22, p.24; Chaloub, S., 1996. A cidade febril, São Paulo, Companhia das Letras; entre outros.
(Rolnik, 1983; Lira, 1991; Marins, 1998) como nos territórios de prostituição (Feldman, 1987). A questão da segregação espacial, por meio da análise das primeiras normas que extrapolam a construção de edifícios contidas nos Códigos de Posturas aprovados na última década do século XIX, em inúmeras cidades, constitui o eixo direcionador de tais análises.

Uma terceira vertente caracteriza-se pela precedência de estudos voltados para os efeitos, repercussões e impactos no espaço urbano com a aplicação da legislação, os quais têm como referência a escala assumida pela expansão das cidades brasileiras mediante estratégias de solução da moradia à margem da legislação: loteamentos clandestinos, cortiços e favelas. Nessa vertente, podem ser discriminados estudos centrados na inefetividade da lei (Grostein, 1987; Rolnik, 1996; Nery Junior, 1998); estudos que enfatizam a relação entre a legislação e a valorização imobiliária (Souza, 1994; Somekh, 1996), e estudos que, com uma visão panorâmica da legislação, apontam seus efeitos no processo de planejamento (Rezende,1997) e na configuração da paisagem urbana (Medina, 1997).

No âmbito da questão da inefetividade da legislação, segundo os procedimentos instituídos de aprovação e fiscalização de loteamentos e da relação poder público/loteador, Grostein (1987) mostra que se consolida uma prática de desobediência consentida e permanente anistia a situações produzidas fora das normas. Rolnik (1997) entende a ineficácia da legislação em regular a produção da cidade como a verdadeira fonte de seu sucesso político, financeiro e cultural, num contexto urbano de concentração de riqueza e poder. A lei age, segundo a autora, como delimitadora das fronteiras do poder, conferindo significados e gerando noções de civilidade e cidadania, mesmo quando não é capaz de determinar a forma final da cidade. A relação entre legislação e valorização imobiliária é analisada por meio do estudo do processo de verticalização, entendido como resultante de uma estratégia de valorização de múltiplas frações do capital (Souza, 1994) e como resultado da multiplicação do solo urbano possibilitada pelo elevador (Somekh, 1996). Numa perspectiva não-historiográfica, estudos sobre os efeitos dos instrumentos normativos vêm sendo realizados em torno de aspectos específicos da legislação, principalmente no que se refere ao zoneamento e aos instrumentos pós-Constituição de $1988 .{ }^{14}$

Esse conjunto de trabalhos representa o início de um processo de construção de uma história da legislação urbanística brasileira e de compreensão do papel que vem desempenhando no desenvolvimento de algumas cidades brasileiras. De modo geral, destacam seu caráter elitista, resultante do diálogo exclusivo entre os órgãos responsáveis por sua elaboração e os setores mais poderosos da sociedade, e seu uso como instrumento de segregação espacial. Há, por vezes, uma supervalorização do papel da legislação na conformação do espaço urbano, o que acarreta que, por meio da legislação, se cristalizem modelos interpretativos genéricos.

As linhas dominantes permitem não só detectar recortes temporais privilegiados pelas pesquisas bem como o nível de aprofundamento da reflexão. O período da Primeira República, no que se refere à perspectiva higienista de controle do espaço urbano, é o mais profundamente estudado e desvendado. Uma explicação plausível para tal predominância é o fato de a questão higienista ter sido amplamente estudada por diferentes disciplinas e o papel da legislação, claramente situado no campo de um projeto político e social. ${ }^{15}$ Nesse sentido, os trabalhos ultrapassam a identificação das leis e penetram nos modelos habitacionais resultantes do ideário higienista, no qual a norma é apenas um dos instrumentos de concretização (Rolnik, 1983; Lira, 1991), nas instituições criadas para a gestão dos territórios e nos procedimentos de aplicação das normas, seja na esfe- 
ra da habitação operária, com a Inspectoria de Hygiene de Pernambuco (Lira, 1991), seja na esfera dos territórios de prostituição, com a Delegacia de Costumes, em São Paulo (Feldman, 1987).

A legislação desse período, embora envolva questôes espaciais, não contém um claro conteúdo urbanístico, e estabelece-se como legislação sanitária. Para os períodos posteriores, quando se constitui uma legislação urbanística stricto sensu, a lógica de construção - dos conceitos às instituições e processos de elaboração e aprovação - ainda se mantém como um campo pouco explorado. Uma vertente emergente de pesquisa vem atuando na perspectiva de desvendar os processos de construção de instrumentos urbanísticos, e não apenas seus efeitos, mediante a análise das referências urbanísticas neles contidas e dos setores e instituições envolvidos em sua formulação e aplicação, na esfera do Executivo e do Legislativo. (Souza, 1994; Grostein, 1987; Feldman, 1996, 1997, 1998; Campos, 1996, 1998). No entanto, a produção é fragmentada, com recortes temporais e espaciais restritos, além de se deter em aspectos específicos da legislação. De fato, há uma concentração de trabalhos sobre São Paulo, Rio de Janeiro e Recife, o que, como nos demais estudos de história urbana, não permite delinear um panorama abrangente da questão, nem discriminar particularidades regionais.

\section{- LUGAR DA LEGISLAÇÃo NO URBANISMO BRASILEIRO}

Uma das questôes fundamentais que permanecem pouco elaboradas na historiografia da legislação urbanística no Brasil se refere ao lugar ocupado pelas normas, a partir do momento em que idéias e práticas urbanísticas são institucionalizadas na administração pública. Uma hipótese que levantamos é a de que, a partir dos anos 40, se consolida uma visão legalista do urbanismo brasileiro. Ao processo de declínio da importância do plano como instrumento de intervenção no espaço urbano corresponde a ascensão da legislação como instrumento por excelência do planejamento. Como mostramos em pesquisa realizada sobre a cidade de São Paulo, no final da década de 1940, inicia-se um processo em que o zoneamento passa a ocupar o lugar do plano e, em pesquisa em desenvolvimento, podemos avaliar essa mudança em escala nacional, e não apenas nos grandes centros urbanos.

Tal processo não é fortuito, e dá-se como parte da introdução, no Brasil, de novos princípios de administração pública, desde os anos 30, numa perspectiva da administração desvinculada da política e do planejamento como técnicas de administração, baseados na teoria administrativa americana da Scientific Management School. Num estudo sobre a reforma do serviço civil no Brasil, no período de 1945 a 1964, Graham (1968) mostra que a introdução dessa abordagem na administração pública no período anterior a 1930 articula-se a uma tradição legalista brasileira, originária dos vínculos com os princípios administrativos da França e Portugal, herdados, por sua vez, da tradição romana.

A visão legalista consiste no enfoque da lei como uma meta em si, e não como um instrumento, entre outros, para se atingir metas, o que leva à preferência por leis antecipatórias em lugar da experimentação, e à crença de que nada pode ser assumido sem prévia legislação ou regulação. A ênfase na lei é, segundo Graham, vista como um ideal, ao invés de algo a ser aplicado a circunstâncias presentes com o máximo de precisão. Para o autor, uma expressão da experiência legal no Brasil é a ênfase e valorização da codificação das leis. 
Os trabalhos de Reis Filho (1968) e Delson (1979) apontam o rigor no estabelecimento de padrões para a construção de cidades, no Brasil, pelos portugueses, desde o século XVIII, mas em que medida a visão legalista se introduz desde as primeiras regulamentações do solo urbano e os matizes que assume ao longo dos séculos XIX e XX representam um campo a ser investigado. O simples arrolamento das leis promulgadas não revela o processo, uma vez que a legislação urbanística é parte de um aparato que constitui o sistema legal (ou Estado legal), variável de país a país, e que repercute nas abordagens de urbanismo e planejamento urbano. O sistema legal não é apenas um conjunto de normas, mas parte constituinte do Estado. Portanto o "Estado legal" é a parte do Estado personificada num sistema legal, que penetra e estrutura a sociedade, fornecendo um elemento básico de previsibilidade e estabilidade às relações sociais, e pressupõe não apenas a promulgação de leis, mas formas de aplicação, caráter público, independência do judiciário etc. ${ }^{16}$ Talvez se pudesse admitir, numa perspectiva braudeliana, que o sistema legal constitui um elemento de longa duração.

A legislação urbanística é, portanto, parte de um determinado sistema legal e de um determinado modelo de gestão que se apóiam em determinada teoria administrativa. Para se entender o papel que a legislação urbanística assume em cada momento do processo de desenvolvimento urbano no Brasil, é necessário desvendar a lógica do sistema legal vigente, assim como as teorias administrativas que informam as estratégias de gestão. É necessário, também, resgatar as instituiçôes que, em cada momento, participaram da formulação e/ou assumiram as funções de aplicação e fiscalização das normas urbanísticas. Por fim, é necessário desvendar os procedimentos adotados, considerando que teorias administrativas engendram modelos institucionais que originam práticas que, por sua vez, se articulam a práticas herdadas de outros momentos. Do ponto de vista das instituições, da organização e dos procedimentos adotados na implementação das leis, alguns trabalhos oferecem uma contribuição relevante, uma vez que utilizam como fontes de pesquisa processos de aprovação das próprias leis, de loteamentos e de edificações (Grostein, 1987; Feldman, 1989, 1996; Simões, 1990; Lira, 1991). Tais fontes de pesquisa permitem, por meio de uma leitura menos genérica, entender a legislação como um processo não-linear, mas como o resultado de embates técnicos e políticos e, ao mesmo tempo, desvendar que relação se estabelece entre cidadão e Estado.

O estudo sistemático das instituições que compõem o sistema legal e os respectivos procedimentos são um caminho, também, para se desvendar o avesso da visão legalista brasileira - a inefetividade das leis -, em cada momento. Se admitirmos que a lei, "em seu conteúdo e em sua aplicação, é basicamente (como é o Estado do qual ela faz parte) uma condensação dinâmica de relaçôes de poder, não apenas uma técnica racionalizada para ordenar as relações sociais", ${ }^{17}$ instituições e procedimentos engendram, em cada momento, diferentes conceitos de controle. Assim, a legislação urbanística, como parte do sistema legal de uma sociedade capitalista enquanto tal, estrutura e garante relaçóes espaciais que são intrinsicamente desiguais, mas os limites entre o legal e o ilegal variam no tempo. São socialmente construídos.

\section{O LUGAR DOS PRESSUPOSTOS MODERNISTAS NA LEGISLAÇÃO URBANÍSTICA}

Um dos aspectos privilegiados nos trabalhos de história urbana produzidos a partir dos anos 80 vem sendo a influência das referências internacionais nas idéias e práticas ur- 
banísticas desenvolvidas no Brasil. De modo geral, esses trabalhos vêm mostrando que, na concepção dos planos elaborados até 1930, dos quais uma parcela significativa - entre planos de melhoramentos, de embelezamento e de conjunto - chegou a ser executada, prevaleceu a influência européia. Os anos 30 aparecem como um momento de transição, em que as influências européias começam a mesclar-se a princípios do urbanismo americano, por meio das parkways, zoneamento, e das versóes americanas das cidades-jardins de Howard, como o princípio das unidades de vizinhança de Radburn. Nas experiências de cidade novas, a partir dos anos 30, começam a ser introduzidos princípios modernistas, que se realizam de forma acabada em Brasília.

Se nos planos as referências internacionais são facilmente demarcadas, seja pelos traçados propostos, seja por explicitaçóes de seus autores em relatórios, textos, memoriais, o mesmo não ocorre em relação à legislação. A legislação é cumulativa. Novas formas de controle com as mais diversas referências são constantemente incorporadas, como peças legais parciais, artigos, num processo contínuo de reformulações, exclusões e acréscimos, que não alteram, necessariamente, nem o sistema legal, nem as instituições e seus procedimentos.

Os estudos mostram que os padrões reguladores portugueses se estabeleceram nas cidades e vilas do Brasil Colônia, e a legislação sanitária do urbanismo higienista de finais do século XIX utiliza as referências inglesas e francesas. As normas de controle de alinhamento e nivelamento das vias, assim como a localização de atividades consideradas nocivas ao meio urbano, as condições de higiene e salubridade das edificações e do espaço público, utilizando princípios de controle e disciplina formulados nas cidades européias, são consolidadas nos chamados Códigos de Posturas Municipais, tornados obrigatórios no final do século XIX. A partir do término dos anos 20, nos chamados Códigos de Obras, permanecem os princípios higienistas europeus, e são identificados princípios da legislação americana, como é o caso, em São Paulo, dos padrões de arranha-céus. A partir dos anos 30, a referência americana se impõe, principalmente na adoção do zoneamento, o qual é incorporado à totalidade da cidade nos Códigos de Obras do Recife, em 1936, e do Rio de Janeiro, em 1937, e em leis parciais em São Paulo, a partir de 1931. ${ }^{18}$ A partir dos anos 30, passam a ser incorporados, também, princípios elaborados no âmbito do movimento moderno.

Podem-se identificar três correntes do pensamento urbanístico, entre as que são referência para o urbanismo no Brasil, que formulam concepçôes de legislação: o urbanismo higienista, que estabelece uma legislação sanitária; o urbanismo americano dos anos 20, que reelabora o zoneamento alemão; e o movimento modernista, que se contrapõe à legislação de princípios higienistas vigente na Europa dos anos 20. Segundo Ebenezer Howard, embora princípios reguladores estejam implícitos na proposta espacial de cidades-jardins, não chegam a propor uma concepção de lei.

As leis sanitárias e o zoneamento americano vêm recebendo a atenção da maioria dos pesquisadores voltados para a historiografia da legislação urbanística no Brasil (Rolnik, 1983; Lira, 1991; Souza, 1994; Feldman, 1996; Somekh, 1997; Nery Junior, 1998; Marins, 1998), e as formas como tais referências foram e são absorvidas pela legislação urbanística brasileira estão sendo desvendadas. Em relação às propostas modernistas, o único documento que vem sendo utilizado como referência é a Carta de Atenas, fundamentalmente no que se refere ao zoneamento funcional.

A análise dos textos produzidos pelos arquitetos vinculados ao movimento modernista no âmbito dos CIAMs (Congressos Internacionais de Arquitetura Moderna) revela que a legislação é colocada como um aspecto fundamental, e suas propostas nesse campo
18 Sobre a influência americana na legislação em São Paulo, ver Feldman, S., 1997. 
vão muito além do zoneamento funcional e da Carta de Atenas. Os arquitetos desenvolveram uma verdadeira concepção de legislação urbanística que tem como eixo principal o questionamento, em múltiplos aspectos, do sistema regulador do urbanismo higienista. A referência à legislação vigente nos anos 20, notadamente na França e na Alemanha, como entrave ao "desenvolvimento da arquitetura", segundo os pressupostos do movimento moderno - soluções para o espaço mínimo para viver, com uma boa iluminação, com plantas livres e flexíveis, com disponibilidade de espaço exterior livre com a construção verticalizada, e viabilizar a produção em série, a "standardização", a racionalização e a economia, que implicam a utilização de novos materiais e novos métodos de construção - é recorrente nos textos.

Os arquitetos vinculados ao movimento modernista apontam, antes de mais nada, a necessidade de se distinguir dois níveis da legislação: o nível urbanístico, que deve tratar dos limites do indivíduo frente à comunidade e dos indivíduos entre si, e o nível da construção e da habitabilidade, que deve assegurar certo grau de qualidade aos edifícios. É no III CIAM, realizado em 1930, em Bruxelas, que se explicita com maior clareza a relação pretendida entre arquitetura e urbanismo. Corbusier propóe que se formulem, juntamente com o sistema urbano adequado à época maquinista, novas leis que devem conter o remembramento de terrenos - "verdadeira revolução na noção sagrada de propriedade", a fim de garantir a melhoria do alcance coletivo, as construções em altura reunidas sobre pequena superfície edificada, enormes espaços livres, supressão de pátios e corredores, construções sobre pilotis, e tetos-jardins. Gropius propõe que, ao invés do limite de altura dos edifícios, se utilize o limite da densidade populacional, ou seja, propõe que se regule a relação entre superfície de moradia/volume edificável/superfície edificável, argumentando que as condiçóes higiênicas e econômicas se tornam mais vantajosas.

É importante destacar que a crítica ao controle de altura envolve aspectos econômico-distributivos (otimização possível por meio de construções laminares), aspectos técnicos (viabilidade de utilização de estruturas em aço ou concreto armado) e, ainda, aspectos formais. Em relação a estes últimos, preconiza a simultaneidade de diferentes tipologias habitacionais em um único complexo edificado, integrado, por sua vez, a serviços ligados à moradia. Nesse sentido, propõe a identificação entre a tipologia da moradia e a tipologia do edifício, o que permitiria a concretização de volumetrias diferenciadas ou repetidas num mesmo conjunto.

Em segundo lugar, destaca a necessidade de a regulamentação assegurar a responsabilidade técnica e social dos produtores das moradias, como também abarcar a responsabilidade da economia do produto. Nesse sentido, as leis devem considerar as inovaçôes nos métodos construtivos, nos conhecimentos higiênicos, nas novas formas de vida propostas pelos arquitetos, sem ignorar as circunstâncias econômicas.

Em terceiro, aponta para a necessidade de flexibilidade da legislação e preconiza a maior participação das entidades de engenheiros e arquitetos no processo de elaboração e aplicação das leis. Assim, excetuando-se as leis que limitam o direito de propriedade, as normas edificatórias não deveriam passar de normas gerais e deveriam permitir a maior liberdade possível na definição do programa da habitação, para o cumprimento das necessidades sociais e higiênicas e para a escolha de materiais e sistemas construtivos.

Em quarto, limita o papel do Estado ao controle da qualidade do produto. Com o mercado livre e com o sistema de produção capitalista, o promotor, o construtor e o usuário podem tornar-se pessoas totalmente independentes. Então, cabe ao Estado proteger os particulares com normas edificatórias contra a ação de especialistas não-qualificados que 
ofereçam moradias de baixa qualidade. Caso o Estado não assuma tal postura, os arquitetos colocam a alternativa da auto-ajuda, estabelecendo-se a relação direta entre o habitante como usuário e o construtor como produtor. O nível de qualidade da moradia passa a ser assunto exclusivo de ambos, e a regulamentação estatal, dessa maneira, passaria a ser supérflua, com o passar do tempo.

Finalmente, preconiza que os arquitetos contem não apenas com a ajuda de diversos setores da ciência e da indústria, como também com a colaboração dos usuários, ao invés de se guiarem apenas pelas leis. Assim, os arquitetos poderão entrar em cena como competidores da construção especulativa de moradias e, ao mesmo tempo, poderão liberar a construção de moradias dos entraves de uma regulamentação anti-social. Considera que o padrão de moradia ideal imposto por uma visão estritamente legalista se mostrou economicamente inviável nas circunstâncias do pós-guerra e, conseqüentemente, as açôes voltadas para a categoria de moradias mais baratas passam a efetivar-se sem que a legislação se responsabilize por elas. Para o estabelecimento de normas ideais, considera imprescindível que o Estado garanta também seu cumprimento econômico em todas as situações, como ocorre com outros tipos de normas.

$\mathrm{Na}$ Carta de Atenas, as considerações sobre a legislação como instrumento para fixar as condições da habitação moderna são uma constante. Nesse documento, que reúne grande parte do repertório da arquitetura modernista, além de incorporar soluções urbanísticas que já vinham sendo utilizadas em cidades européias e americanas, Corbusier (1941) preconiza a "urgência de regulamentar, por um meio legal, a disposição de todo solo útil para equilibrar as necessidades vitais do indivíduo em harmonia com as necessidades coletivas". Essa postura de Corbusier - inovadora em relação à legislação - já estava presente em sua intervenção no III CIAM, em 1930, quando afirma que o objetivo do Congresso, realizado em torno do tema "Métodos Construtivos Racionales. Casas Bajas, Medias y Altas", é chegar a uma modificação da legislação municipal em diversas cidades do mundo. As propostas modernistas, segundo o arquiteto, não admitem uma mudança parcial da legislação, mas exigem que se estabeleça um conjunto de novas regras, que devem partir do reagrupamento do solo - "único caminho que conduz ao urbanismo" -, uma vez que a propriedade subdividida, o caráter inalienável da propriedade, condena "toda tentativa de melhorias coletivas". ${ }^{19}$

$\mathrm{Na}$ verdade, as propostas modernistas para a legislação podem ser interpretadas como a proposta de um novo sistema legal, e algumas questôes permanecem no debate atual sobre a legislação urbanística no Brasil, embora não se explicite tal vínculo. Suas propostas envolvem aspectos formais para a tradução das soluções de edifícios e para a organização do espaço urbano, além de questôes técnicas, mas também aspectos econômicos e sociais que se realizam no processo de elaboração e decisão sobre a aplicação das leis, e que pressupõem a redefinição das relações entre o Estado e os demais atores envolvidos na construção das cidades. Além disso, num evidente propósito de deslocar médicos e engenheiros deste campo de atuação, o papel atribuído aos arquitetos e suas associações é destacado. ${ }^{20}$

$\mathrm{O}$ estudo, ainda em processo, de como esse elenco de questões relativas à regulamentação foi assimilado, no Brasil, pelos responsáveis pela elaboração das leis, por arquitetos e engenheiros responsáveis por projetos de cidades novas e de habitações econômicas, vem demonstrando que se dá de forma bastante limitada. No âmbito dos debates em torno da legislação, a partir dos anos 30, as concepções modernistas têm repercussão significativa. Em congressos e periódicos de entidades de arquitetos e engenheiros, a reivindicação por mudanças nos códigos de obras com o intuito de atenderem a um novo tempo é recorrente.
19 A intervenção de Le Corbusier no III CIAM foi "La parcelación del suelo em las ciudades", In: Aymonino, 1973.

20 No II Congresso Internacional de Arquitetura Moderna, realizado em Frankfurt am Main, em 1929, a legislação foi objeto de uma das quatro exposiç̃ones que direcionaram as discussões. Os temas foram "Ordenanzas edificatorias y vivienda minima", apresentado por Hans Schmidt; "Los fundamentos sociológicos da la vivienda mínima (para la población obrera de la ciudad)", apresentado por Walter Gropius; "Analisis de los elementos fundamentales en el problema de la vivienda mínima", por Le Corbusier e Pierre Jeanneret, e "La organización de la vivienda mínima", apresentado por Victor Bourgeois (Aymonino, op.cit.). 
21 Destacam-se nesses debates, entre outros, o engenheiro Alexandre de Albuquerque, presidente do Congresso de Habitação de 1931, e Armando de Godoy, engenheiro da Diretoria de Engenharia do Distrito Federal.

22 Decreto $n^{0} 7$ de 12/06/1960.

Sarah Feldman, arquiteta, é professora do Departamento de Arquitetura e Urbanismo da Universidade de São Paulo.

E-mail: sarahfel@sc.usp.br
A V A N Ç O S E L I M I T E S N A H I S T O R I O G R A F I A

A simplificação das leis, a maleabilidade para se atender aos materiais e técnicas modernas de construção, a incorporação de setores da sociedade para a redação das leis conjuntamente com técnicos são questões enfocadas por engenheiros, arquitetos e urbanistas. ${ }^{21}$

Nos anos 30, esboça-se na legislação de uso e ocupação do solo uma ruptura com a concepção centrada na edificação e fortemente marcada pela visão higienista que se inicia com os Códigos de Posturas do final do século XIX. Essa ruptura se dá, fundamentalmente, com a introdução de elementos reguladores de abrangência urbanística e de uma visão de urbanismo que se justifica explicitamente em termos econômicos. Parte dessa mudança se verifica com a introdução do zoneamento abrangente no conjunto da cidade, seguindo o modelo adotado no início do século em Nova York, e não do zoneamento proposto por Le Corbusier. Este só se efetivará em 1960, com a aprovação das "Normas para Construção em Brasília”. 22

Nas demais cidades brasileiras - novas ou existentes, os códigos de obras assimilarão dos modernistas, num primeiro momento, os princípios de ocupação do lote que relacionam altura de edifícios e solo livre, e, posteriormente, padrões de ocupação para grandes conjuntos residenciais, com a definição de espaços coletivos, ruas exclusivas para pedestres etc. Ambas as estratégias evoluem para um processo de gradativa mudança dos tecidos urbanos existentes e podem ser interpretadas como formas de reagrupamento do solo. Essa é, sem dúvida, a mais significativa influência do ideário modernista que se realiza mediante mecanismos reguladores do uso e ocupação do solo.

A análise das referências modernistas na legislação urbanística, assim como de outras referências que formularam concepções de legislação, exigem a identificação das estratégias utilizadas para as transferências. $\mathrm{O}$ foco da pesquisa sobre legislação unicamente no enunciado das leis vem-se mostrando insuficiente. Tomando Brasília como exemplo, pode-se observar que a legislação aprovada logo após a inauguração da capital absorveu os princípios formais das propostas modernistas, e foi, sem dúvida, formulada por arquitetos, uma vez que a categoria vem, há décadas, assumindo a função de legisladores, no Brasil. No entanto, a peça legal de 1960 foi, assim como grande parte da legislação urbanística no Brasil, aprovada por decreto, ou seja, ocorrem mudanças que atendem aos requisitos formais, os arquitetos conquistam um espaço como formuladores de leis, mas tudo isso se incorpora ao sistema legal preexistente no Brasil.

O estudo da legislação sob a ótica modernista torna evidente a necessidade de se discutir a questão metodológica para interpretar as permanências e mudanças na legislação urbanística. Um caminho possível talvez esteja na identificação dos tempos propostos por Braudel: discriminar o que permanece constante durante um tempo longo, evoluindo de maneira imperceptível; o que flutua, oscila de forma cíclica, e o que não passa de acontecimento, representando rupturas ou restabelecimento de equilíbrios. Talvez seja esse um dos caminhos para se entender o passado e formular propostas para o presente.

\section{REFERÊNCIAS BIBLIOGRÁFICAS}

\author{
ANDRADE, F. de P. D. de. Subsídios para o estudo da influência da legislação na ordena- \\ ção e na arquitetura das cidades brasileiras. São Paulo, 1966. Tese (Doutorado) - \\ EPUSP. \\ AYMONINO, C. La vivienda racional. Barcelona: Gustavo Gili, 1973. \\ BORGES, V. P. O que é história. São Paulo: Editora Brasiliense, 1993.
}


BOURGEOIS, V. "La organización de la vivienda minima”. In: AYMONINO, C. La vivienda racional. Barcelona: Gustavo Gili, 1973.

BRESCIANI, M. S. "Permanência e ruptura no estudo das cidades". In: FERNANDES, A., FILGUEIRAS GOMES, M. A. Cidade e História. Salvador: UFBA/Anpur, 1992.

BURKE, P. A Escola dos Annales 1929-1989: A revolução francesa da historiografia. São Paulo: Editora Unesp, 1991.

. A escrita da história: novas perspectivas. São Paulo: Editora Unesp, 1992.

CAMPOS, C. "Urbanismo equitativo: o debate da taxa de melhoria e suas ressonâncias em São Paulo (1920-1945)". Anais do IV Seminário de História da Cidade e do Urbanismo. Rio de Janeiro: Prourb, vol. I., p. 205-214, 1996.

. "Em nome da cidade: introdução e apropriação do urbanismo nos debates da Câmara paulistana na década de 20". Anais do IV Seminário de História da Cidade e do Urbanismo. Campinas: Faupuccamp, cd-rom, 1998.

DECCA, E. de et al. "Depoimentos: cidade e história”. Revista Espaço e Debates. São Paulo, Neru, n. 34, 1991.

DELSON, R. M. Novas vilas para o Brasil-Colônia. Planejamento espacial e social no século XVIII. Brasília: Editora Alva, 1997.

FELDMAN, S. Segregaçôes espaciais urbanas: A territorialização da prostituição feminina em São Paulo. São Paulo, 1989. Dissertação (Mestrado) - Faculdade de Arquitetura e Urbanismo da Universidade de São Paulo.

. Planejamento e zoneamento. São Paulo, 1947-1972. São Paulo, 1996. Tese (Doutorado) - Faculdade de Arquitetura e Urbanismo da Universidade de São Paulo.

"A americanização do setor de urbanismo da administração municipal de São Paulo". Anais do IV Seminário de História da Cidade e do Urbanismo. Rio de Janeiro: Prourb. vol. I., p. 225-234, 1996.

. "O zoneamento ocupa o lugar do plano: São Paulo, 1947-1972". Anais do 70 Encontro Nacional da Anpur. Recife: MDU/UFPE, p. 667-684, 1997.

"Anhaia Mello e a Comissão do plano: o plano para além da esfera técnica". Anais do IV Seminário de História da Cidade e do Urbanismo. Campinas: Faupuccamp, cd-rom, 1998.

FILGUEIRAS GOMES, M. A., FERNANDES, A. "A Pesquisa recente em história urbana no Brasil: percursos e questôes”. In: PADILHA, N. (Org.). Cidade e urbanismo. História, teorias e práticas. Salvador: MAU/UFBA, 1998.

FRIDMAN, F., RAMOS, C. A. "A História da Propriedade da Terra no Brasil". In: FERNANDES, A.; FILGUEIRAS G. M. A. (Orgs.). Cidade \& história. Salvador: UFBA/Anpur, 1992.

FRIDMAN, F. “Os donos da terra carioca”. Espaço e Debates. São Paulo, Ano XIV, n. 37, 1994.

GRAHAM, L. S. Civil service reform in Brazil - principles versus practice. Austin \& London: University of Texas Press, 1968.

GROPIUS, W. "Los fundamentos sociológicos de la vivienda minima (para la población obrera de la ciudad)". In: AYMONINO, C. La vivienda racional. Barcelona: Gustavo Gili, 1973.

GROSTEIN, M. D. O papel da 'Irregularidade na estruturação do espaço urbano no município de São Paulo. 1900-1987. São Paulo, 1987. Tese (Doutorado) - Faculdade de Arquitetura e Urbanismo da Universidade de São Paulo. 
A V A N Ç O S E L I M I T E S N A H I S T O R I O G R A F I A

HANDLIN, O., BURCHARD, J. The historian and the city. The MIT Press, 1963, ed.1966.

JANINE, R. et al. "Nova história e seus velhos dilemas". Revista USP, São Paulo, n. 23, set-nov, 1994.

LE CORBUSIER, JEANNERET, P. "Analisis de los elementos fundamentales en el problema de la vivienda minima”. In: AYMONINO, C. La vivienda racional. Barcelona: Gustavo Gili, 1973.

LE CORBUSIER. "A Carta de Atenas”. São Paulo: Edusp/Hucitec, 1941, ed.1993.

LE GOFF, J. A história nova. São Paulo: Editora Martins Fontes, 1993.

LIRA, J. T. C. de. "O germe da lei urbana e a higiene da casa (e) do operário". Anais do IV Encontro Nacional da Anpur. Salvador, 1991.

MARINS, P. C. G. "Habitação e vizinhança: limites da privacidade no surgimento das metrópoles brasileiras". In: SEVCENKO, N. (Org.). História da vida privada no Brasil-3. São Paulo: Companhia das Letras, 1998.

MAY, E. "La vivienda para el minimo nivel de vida". In: AYMONINO, C. La vivienda racional. Barcelona: Gustavo Gili, 1973.

NERY JUNIOR, J. M. "Discursos de Anhaia Mello e de Prestes Maia sobre o zoneamento: coerências e contradições entre postulados teóricos e políticas no urbanismo paulistano". Anais do V Seminário de História da Cidade e do Urbanismo. Campinas: Faupuccamp, cd-rom, 1998.

MEDINA, L. "A legislação de uso e ocupação do solo do Recife como instrumento de desenho urbano". Anais do VII Encontro Nacional da Anpur. Recife, MDU/UFPE, 1997.

O’DONNELL, G. "A (in)efetividade da lei na América Latina”. Novos Estudos Cebrap, São Paulo, n. 51, Julho, 1998.

REIS FILHO, N. G. Contribuição ao estudo da evolução urbana no Brasil: 1500-1720. São Paulo: Livraria Pioneira, 1968.

REZENDE, V. F. "A evolução dos instrumentos de controle do espaço urbano na Cidade do Rio de Janeiro. É possível planejar o futuro através da Legislação?”. Anais do IV Seminário de História da Cidade e do Urbanismo. Rio de Janeiro: Prourb, vol. II, 1996.

ROLNIK, R. A cidade e a lei. São Paulo: Studio Nobel/Fapesp,1995.

SCHMIDT, H. "Ordenanzas edificatorias y vivienda minima”. In: AYMONINO, C. La vivienda racional. Barcelona: Gustavo Gili, 1973.

SIMÕES, J. G. O setor de obras públicas e as origens do urbanismo na Cidade de São Paulo. São Paulo, 1990. Dissertação (Mestrado) - Fundação Getúlio Vargas.

SOMEKH, N. A cidade vertical e o urbanismo modernizador. São Paulo: Studio Nobel/ Fapesp, 1996.

SOUZA, M. A. A identidade da metrópole. São Paulo. Editora Hucitec/Edusp, 1994.

SUTCLIFFE, A. The history of urban and regional planning - an annotated bibliography. London: Mansell,1981.

VEYNE, P. Como se escreve a história. Lisboa: Ediçōes 70, 1971.

ABSTRACT This paper analyses recent developments in the history of Brazilian urban legislation, pointing out the progress made and limits faced, as a basis for reflection in the debate on urban development and planning practice. The analysis is divided into three parts. The first 
relates the dissemination of urban historical research in Brazil to the expansion of the field of history which began in the 1960s with the "New History" movement in Europe and the United States. The second part sets out the dominant and emerging approaches to urban legislation. Finally, there is a discussion of two aspects that are seen as gaps in the history of urban legislation: the role of norms, as the ideas and practices of urban planning become institutionalised within public administration, and the influences of modernist ideas on Brazilian urban legislation, taking into account that the modern movement proposes a new legal system for urban planning.

KEYWORDS Urban legislation; history; modernist movement. 